\title{
Sub-solvus Cellular Recrystallization and P Phase Formation in a Single-Crystal Superalloy Containing Re
}

\author{
Long-Chao Zhuo $\cdot$ Ming Huang $\cdot$ Ji-Chun Xiong $\cdot$ Jia-Rong Li $\cdot$ Jing Zhu
}

Received: 19 July 2014/Revised: 20 August 2014/Published online: 21 November 2014

(C) The Chinese Society for Metals and Springer-Verlag Berlin Heidelberg 2014

\begin{abstract}
Sub-solvus recrystallization behavior of a second-generation single-crystal superalloy has been studied by transmission electron microcopy and scanning transmission electron microcopy. Surface local stress facilitated cellular recrystallization accompanied with formation of twin structure and TCP phase of $P$ during annealing at sub-solvus temperature of $1,100{ }^{\circ} \mathrm{C}$. The precipitation of $P$ phase is considered to be attributed to the coarsening of $\gamma^{\prime}$ phase in the recrystallized aggregates which lower the activation energy for atomic migration.
\end{abstract}

KEY WORDS: Nickel-based single-crystal superalloys; Interfaces; Recrystallization; Twin boundary; STEM

\section{Introduction}

The removal of high-angle grain boundaries that serve as sites for damage accumulation and failure has permitted continued advances in the development of nickel-based single-crystal superalloys, leading to extensive use for turbine blades and vanes in heat engines under extreme conditions and long-term exposure [1, 2]. In industrial practice, single-crystal superalloys are usually fabricated by investment casting technique, and some ramifications of this technique compromising the integrity of the material

Available online at http://link.springer.com/journal/40195

L.-C. Zhuo · M. Huang · J. Zhu ( $\)$

The State Key Laboratory of New Ceramics and Fine Processing, Laboratory of Advanced Materials (MOE), School of Materials Science and Engineering, National Center for Electron Microscopy in Beijing, Tsinghua University, Beijing 100084, China

e-mail: jzhu@mail.tsinghua.edu.cn

J.-C. Xiong · J.-R. Li

Science and Technology on Advanced High Temperature Structural Materials Laboratory, Beijing Institute of Aeronautical Materials, Beijing 100095, China need to be highly recognized. Local residual stresses, inextricably generated as a result of the differences in thermal expansion coefficients of alloy and ceramic core during solidification, or removal of ceramic shell and core, or surface repair by grit blasting for assembling or ensuring acceptable substrate condition for thermal barrier coating adherence [3, 4], can be of a magnitude sufficient to cause plastic yielding $[5,6]$. Accompanying manufacturing and subsequent heat treatments, or during further rigorous longterm service, the thermal-mechanical prerequisite would facilitate the occurrence of recrystallization in the internal surfaces, which are known to act as nucleation site for fatigue cracks and reduce significantly the creep rupture strength and fatigue life [7], due to the lower modulus and higher Schmid factors in the recrystallized areas [8]. Therefore, the investigation on phase stability or recrystallization phenomenon of superalloys has been of vital importance in preventing catastrophic consequences.

However, among the extensive studies, more attention was paid to wrought $[9,10]$ and powder metallurgy [11, 12] superalloys, where recrystallization is an effective approach to optimizing microstructure through grain refinement, texture control, and relief of deformation stresses. By contrast, on directionally solidified or single- 
crystal superalloys, for which recrystallization is detrimental, the limited open literatures were reported. Usually, thermal stability of multicomponent superalloys is hard to predict, due to the lack of knowledge regarding precipitation kinetics and quantitative information about the nature of the local stress state. For this reason, with reliance placed on existing casting experience and practice, recent research has been carried out to investigate the effect of applied stress [13], heat treatment parameters [14], as well as the microstructural features such as residual eutectics and carbides $[15,16]$ on recrystallization behaviors in several single-crystal superalloys. Nevertheless, detailed information concerning the early stage of recrystallization, especially for cellular process of discontinuous precipitation, involving nucleation and growth of recrystallized grains, migration of grain boundaries, as well as elemental segregation is still insufficient. Here in this paper, special attention has been paid on the cellular recrystallization (CR) process to study the thermal stability of grit-blasted DD6 annealed at $\gamma^{\prime}$ sub-solvus temperature of $1,100{ }^{\circ} \mathrm{C}$.

\section{Materials and Methods}

The second-generation single-crystal superalloy DD6 [17] with tensile and creep rupture properties comparable to SC180, René N5, CMSX-4, and PWA1484, was used to study the thermal stability of nickel-based single-crystal superalloys. The nominal chemical composition of the DD6 alloy used in the present work is $4.3 \mathrm{Cr}, 9 \mathrm{Co}, 2 \mathrm{Mo}$, $8 \mathrm{~W}, 7.5 \mathrm{Ta}, 2 \mathrm{Re}, 0.5 \mathrm{Nb}, 5.6 \mathrm{Al}, 0.1 \mathrm{Hf}$, and balance $\mathrm{Ni}$ (in weight percentage). Single-crystal plate of the alloy, $160 \mathrm{~mm}$ in length, $24 \mathrm{~mm}$ in width, and $12 \mathrm{~mm}$ in thickness was directionally solidified in Bridgman furnaces. Details of DD6 preparation have been described previously [17]. Longitudinal orientation of the plate is within $15^{\circ}$ deviating from [001] direction. In order to avoid additional surface deformation, electric discharge machine (EDM) was used to cut the plates into small pieces $(11 \mathrm{~mm} \times 11 \mathrm{~mm} \times 8 \mathrm{~mm})$, with the $11 \mathrm{~mm} \times 11 \mathrm{~mm}$ plane parallel to the [001] direction. The single-crystal pieces were grit blasted at a pressure of $0.25 \mathrm{MPa}$ on the $11 \mathrm{~mm} \times 11 \mathrm{~mm}$ plane for $30 \mathrm{~s}$. $\mathrm{SiO}_{2}$ spheres with a radius of $75 \mu \mathrm{m}$ were used. The grit-blasted pieces were tubed in vacuum silica glass to avoid oxidation, and then subjected to heat treatment. Sub-solvus cellular recrystallization process in the surface region has been studied on grit-blasted DD6 annealed at $1,100{ }^{\circ} \mathrm{C}$ for 4 and $16 \mathrm{~h}$, followed by air cooling. Then, the samples were cut along the section parallel to the recrystallized surface by EDM, followed by carefully grinding to thickness of $30 \mu \mathrm{m}$ with the fine metallographic grinding papers $(1,000-5,000$ grit) from the opposite side to the free surface. Disks with diameters of $3 \mathrm{~mm}$ suitable for transmission electron microcopy (TEM) and scanning transmission electron microcopy (STEM) observations were punched out of samples, and thin foils were prepared by electrochemical polishing. The microstructure of the samples was studied using a JEOL 2010F field emission TEM. The high-angle annular dark-field (HAADF) detector was used for Z-contrast imaging and the X-ray energy dispersive spectrometer (EDS) for microanalysis, which are equipped in the STEM.

\section{Results and Discussion}

Characteristic microstructural features of annealed samples at $1,100{ }^{\circ} \mathrm{C}$ for $4 \mathrm{~h}$ are captured as shown in Fig. 1. Figure 1a shows the serrated and bulging recrystallization reaction front, with newly precipitated CR aggregate on the upper right. Driven by both the local reduction of chemical-free energy and strain energy reduction [18], the incoherent highangle reaction front $[7,19]$ would provide a high-diffusivity channel for redistribution of alloying elements, and assist the further progress of reaction front or consumption of the surrounding dislocation networks introduced by grit blasting. In addition, since the dissolution process of $\gamma^{\prime}$ precipitates exhibits a strong size-dependent behavior [20] and residual stresses assist dissolution of the existing phases [21], therefore in sub-surface layers of the present material, microstructural inhomogeneities [22] enable partial dissolution of $\gamma^{\prime}$ precipitates ahead of the reaction front at sub-solvus temperature of $1,100{ }^{\circ} \mathrm{C}$, as captured in Fig. 1a. This would further assist the supersaturation of the interface by the feeding of solute, accelerating subsequent growth of CR aggregates during heat treatment, which agrees with the phenomenon occurred in discontinuous precipitation of polycrystalline superalloys [9].

Generally, annealing twins are key features in the microstructure of recrystallized materials having low to medium stacking fault energy. As discussed by Haasen [23] and Mahajan [24], the relatively low stacking fault energy of approximately $20-30 \mathrm{~mJ} / \mathrm{m}^{2}$ for $\gamma$ phase and the mobile high-angle grain boundary would facilitate the formation of annealing twins [25]. This has been experimentally observed in certain area of the CR aggregates. A bright field image with the selected area electron diffraction (SAED) pattern in the inset is shown in Fig. 1b. It should be noted that twinning boundaries would provide an intrinsically higher resistance to fatigue cracking than general recrystallization boundaries during creep rupture [26].

With increasing annealing time as shown in Fig. 2, interfaces of the $\mathrm{CR}$ aggregates further progressed and impinged with each other. Figure $2 \mathrm{a}$ shows an incomplete annihilation of dislocation network in the original singlecrystal matrix consumed by growing $\mathrm{CR}$ aggregates. 

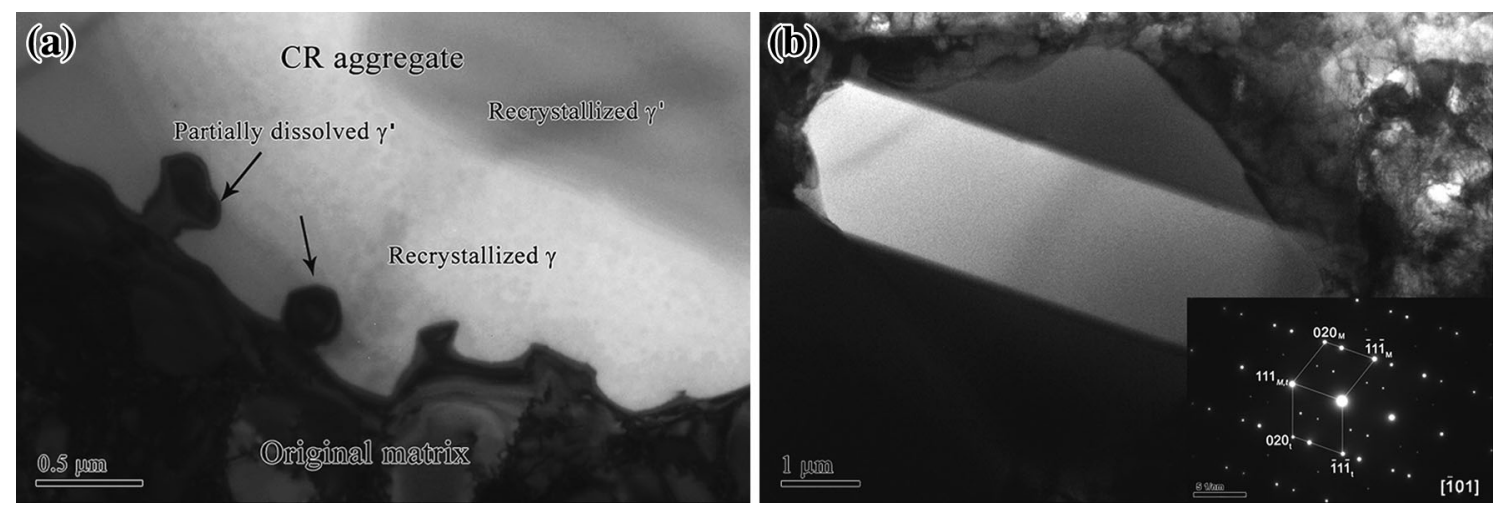

Fig. 1 Bright field TEM images of typical CR aggregate a, twin formation with the SAED pattern inserted $\mathbf{b}$, taken from the specimen annealed at $1,100{ }^{\circ} \mathrm{C}$ for $4 \mathrm{~h}$
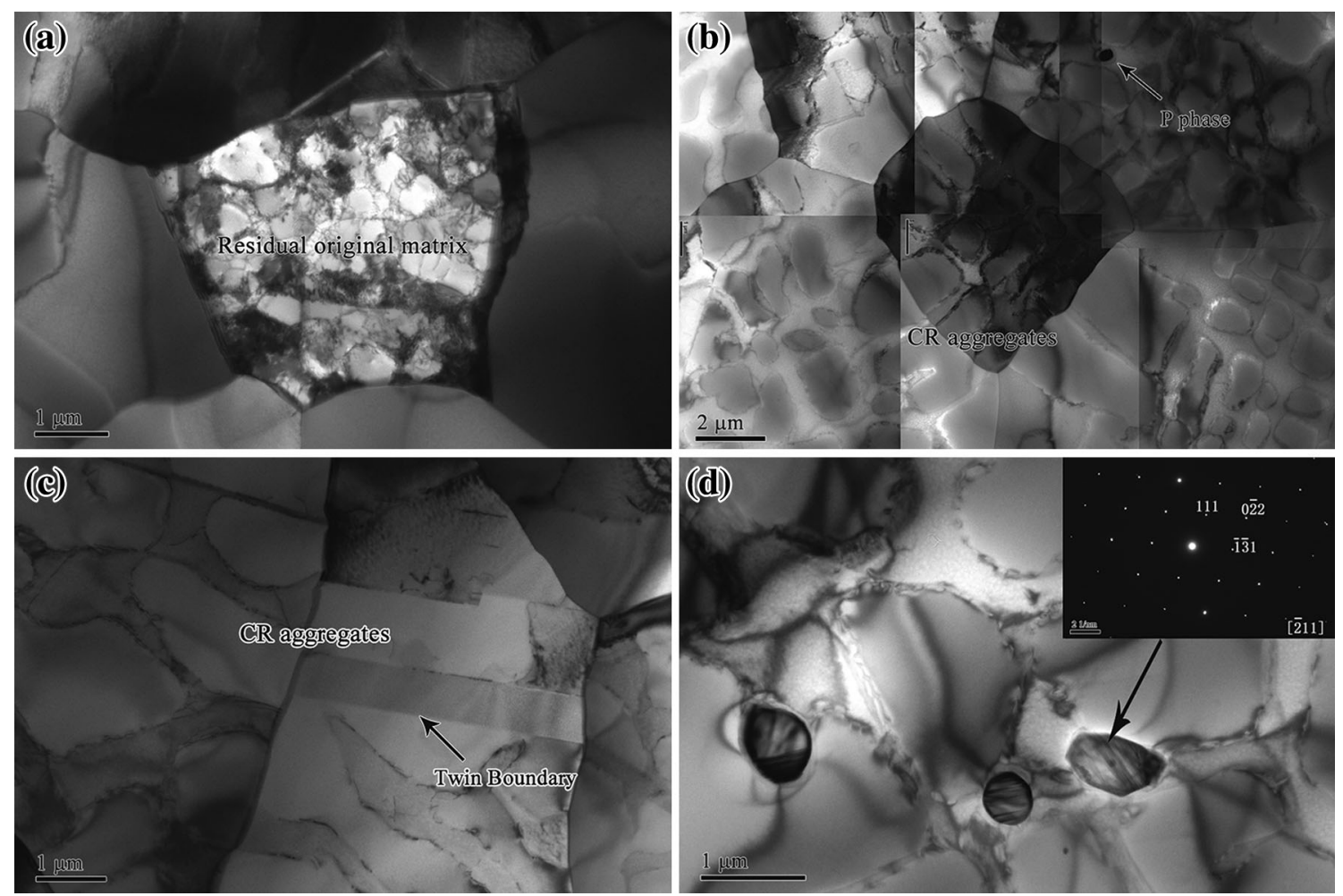

Fig. 2 Bright field TEM images of further developed CR aggregates a-c, P phases with one SAED pattern inserted d, for the specimen annealed at $1,100{ }^{\circ} \mathrm{C}$ for $16 \mathrm{~h}$

Figure $2 \mathrm{~b}$ presents the impingement of fully developed CR aggregate colonies, which would result in a substantial reduction in creep and fatigue properties since the aggregate boundaries serve as channels of crack initiation and propagation during deformation [7]. Meanwhile, twin structure has also been detected in certain recrystallized aggregates after long-term annealing (Fig. 2c).

Besides, an orthorhombic topologically close-packed (TCP) phase of $\mathrm{P}$ (space group: Pbnm, lattice parameters: $a=1.698$, $b=0.475, c=0.907 \mathrm{~nm}$ ) [27] was found to precipitate in certain recrystallized aggregates (Fig. 2d). The SAED pattern taken from the [2 111$]$ zone axis of one $\mathrm{P}$ phase is inserted in Fig. 2d. Quantitative composition determination via EDS shows that the TCP phase can be formulated as $\mathrm{W}_{20.3} \mathrm{Re}_{14.7} \mathrm{Mo}_{6.9} \mathrm{Ta}_{1.4} \mathrm{Nb}_{0.4} \mathrm{Cr}_{12.1} \mathrm{Ni}_{29.3} \mathrm{Co}_{20.3}$. Although the alloying elements in the multicomponent superalloy are complicated, certain elements exhibit similar effects on stability and occupation of sublattices in the TCP phases [28]. Accordingly, the equivalents are grouped and the composition can be written as (WMoReTaNb) ${ }_{43.7} \mathrm{Cr}_{12.7}(\mathrm{NiCo})_{49.6}$, which shows good agreement with previous reported composition of $P$ phase. 


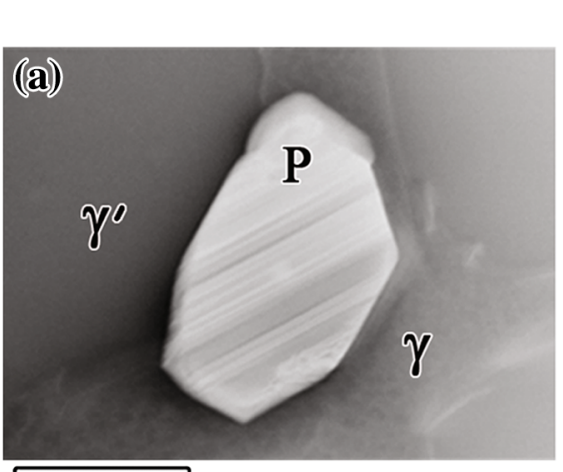

$500 \mathrm{~nm}$

$\mathrm{Co} K \alpha 1$

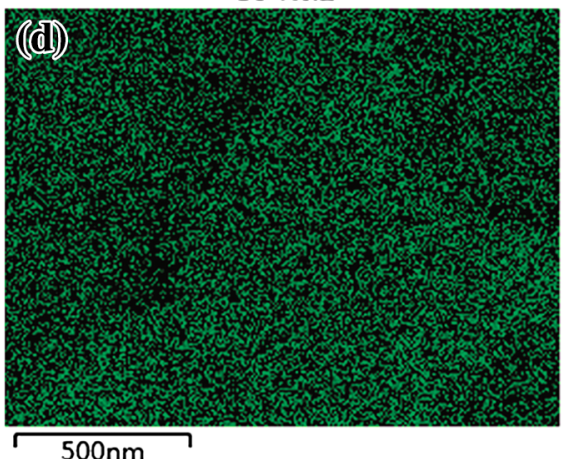

$\mathrm{Cr} \mathrm{K} \alpha 1$

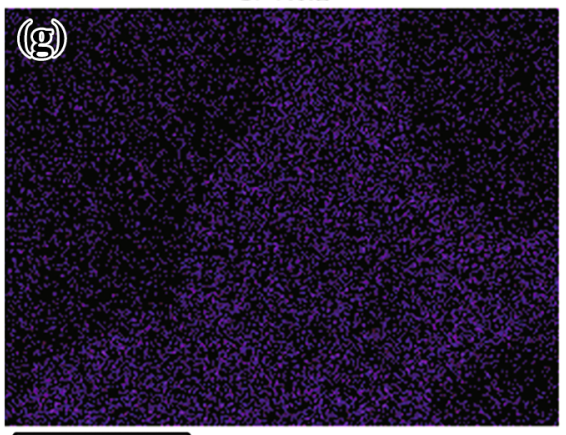

$500 \mathrm{~nm}$
$\mathrm{Ni} K \alpha 1$

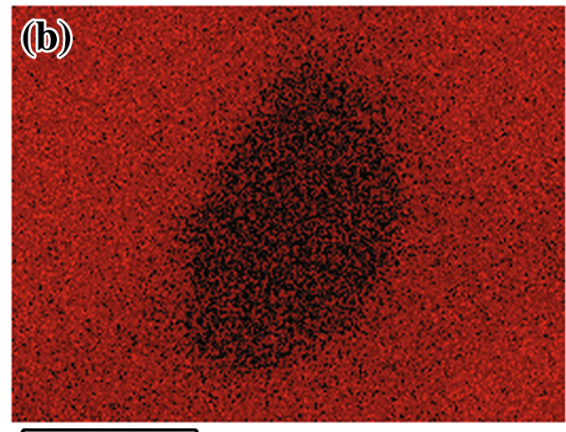

$500 \mathrm{~nm}$

Al Ka1

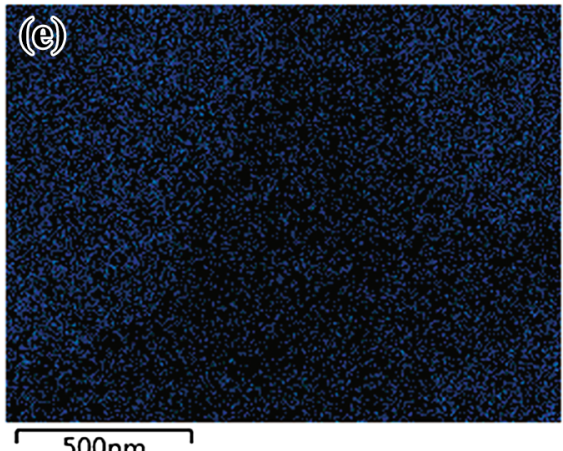

$\operatorname{Re} \operatorname{L} \alpha 1$

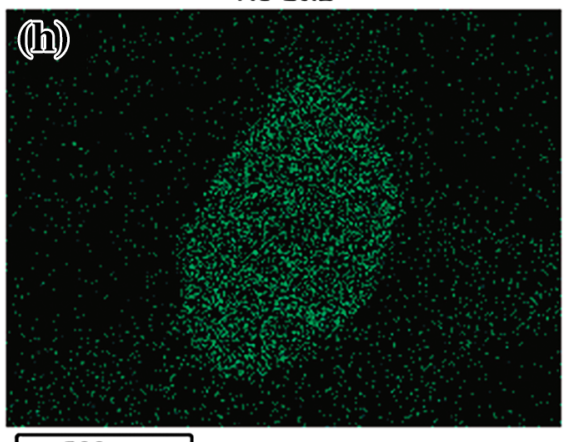

$500 \mathrm{~nm}$
Ta $L \alpha 1$

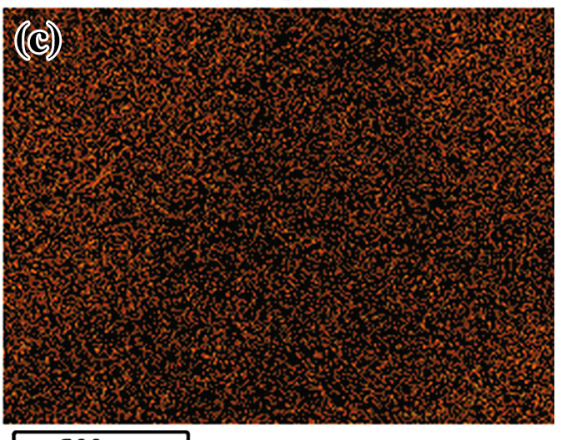

W La1

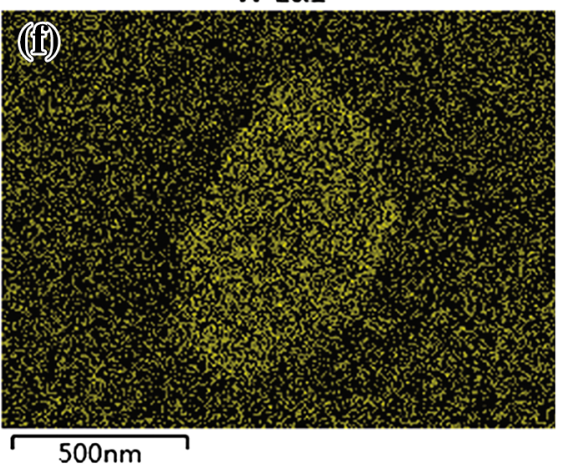

Mo Kal

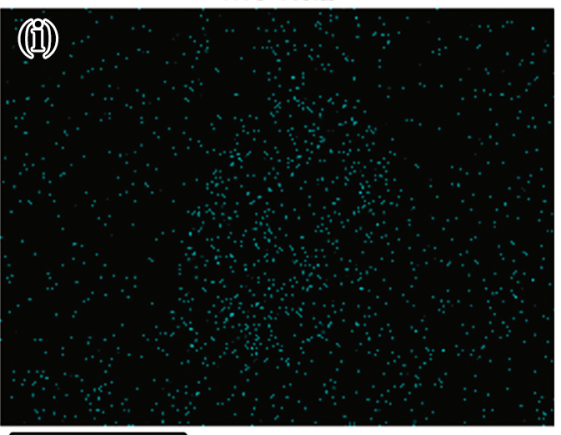

$500 \mathrm{~nm}$

Fig. 3 HAADF image a of P phase, $\gamma$ and $\gamma^{\prime}$ in one CR aggregate of the Ni-based single-crystal superalloy, and corresponding mapping images of the elements $\mathrm{Ni}, \mathrm{Ta}, \mathrm{Co}, \mathrm{Al}, \mathrm{W}, \mathrm{Cr}, \mathrm{Re}$, and $\mathrm{Mo} \mathrm{b}-\mathbf{i}$

As is known, for increasing thermal efficiency and remarkable resistance to creep deformation, significant higher levels of refractory elements are added to most modern single-crystal superalloys [29]. Inevitable negative effect resultant from this is the potential promotion of phase instabilities that lead to the formation of mechanically detrimental TCP phases during exposure to elevated temperatures. It is thereby crucial to take the possible occurrence of these phases into account since it can significantly change the phase relations and the alloy chemistry. To investigate the local elemental distribution, Fig. 3a shows an HAADF image of an area including the recrystallized $\gamma, \gamma^{\prime}$, and $\mathrm{P}$ phases in the Ni-based singlecrystal superalloy annealed at $1,100{ }^{\circ} \mathrm{C}$ for $16 \mathrm{~h}$. Variations can be observed in the image contrast in the $\mathrm{P}$ phase. The mapping images of $\mathrm{Ni}, \mathrm{Ta}, \mathrm{Co}, \mathrm{Al}, \mathrm{W}, \mathrm{Cr}, \mathrm{Re}$, and $\mathrm{Mo}$ are shown in Fig. 3b-i, respectively. As indicated by its brighter contrast in the HAADF image in Fig. 3a, the P phase consists of higher concentration of heavy elements compared with other areas. Enrichment of the W, Re, and Mo can be clearly observed in the $\mathrm{P}$ phase, especially $\mathrm{W}$ and Re. Therefore, the formation of $\mathrm{P}$ phase causes the depletion of strengthening elements which are most effective at conferring resistance to creep in the matrix, and serves as damage accumulation or crack initiation sites during service since its inherent brittleness. As the primary element in the construction of the matrix, $\mathrm{Ni}$ is more likely to remain in the $\mathrm{CR}$ region to maintain the stability of the 
matrix structure. It should also be noted that the elements including $\mathrm{Ta}, \mathrm{Co}, \mathrm{Al}$, and $\mathrm{Cr}$ distribute evenly across the $P / \gamma$ interface, indicating no obvious preference. In contrast, in well accordance with relative sharp contrast across the $\gamma / \gamma^{\prime}$ interface, similar trend can be seen across the $P / \gamma^{\prime}$ interface.

On the basis of the molecular orbital calculations of electronic structures, the $M_{\mathrm{d}}$ electron methods [30] have been reported to have predictive capability for the avoidance of TCP precipitation. The calculated $M_{\mathrm{d}}$ of 0.982 for present studied DD6 also indicates its instability. However, since the growth of TCP is controlled by the bulk volume diffusion of TCP-forming elements [31], and the dense refractory elements especially for Re have very low diffusion coefficient in matrix $\gamma$ [32], therefore after long-term annealing here, neither TCP precipitation nor recrystallization has occurred in the inner strain-free matrix distantly away from the surface. Accordingly, it can be easily concluded that the precipitation of TCP in the surface region could be attributed to the coarsening of $\gamma^{\prime}$ phase in the strain-induced recrystallized aggregates. Gradual growth of $\gamma^{\prime}$ particles can promote supersaturation of $\gamma$-forming elements such as Re and $\mathrm{W}$ in the direct vicinity of $\gamma^{\prime}$ phases, thereby lowering the activation energy for atomic migration and increasing the driving force for its precipitation. Another possible reason for the concentration of high refractory elements and precipitation of $\mathrm{P}$ phase may be the elemental vaporization with the extent of $\mathrm{Ni}$ and $\mathrm{Al}$ loss in the surface region during long-term annealing [33], which has also been recently detected in a grit-blasted CMSX-10N alloy [34].

\section{Conclusions}

Surface recrystallization behavior of a second-generation single-crystal superalloy DD6 was studied experimentally by annealing at $1,100{ }^{\circ} \mathrm{C}$ for 4 and $16 \mathrm{~h}$. With increasing annealing time, cellular recrystallized aggregates gradually consumed the surrounding dislocation networks in the original single-crystal matrix. Partial dissolution of the $\gamma^{\prime}$ phase ahead of the recrystallization front and twin structure formation were detected. Besides, an intermetallic TCP phase of $\mathrm{P}$ was identified to precipitate in certain recrystallized aggregates, which is considered to be attributed to the coarsening of $\gamma^{\prime}$ phase in the recrystallized aggregates that lower the activation energy for atomic migration, and the elemental vaporization with the extent of $\mathrm{Ni}$ and $\mathrm{Al}$ loss in the surface region during long-term annealing.

Acknowledgments This work was financially supported by National 973 Project of China (No. 2015CB654902) and National Nature Science Foundation of China (Nos. 11374174 and 51390471). This work made use of the resources of the National Center for Electron Microscopy in Beijing.

\section{References}

[1] R.C. Reed, The Superalloys: Fundamentals and Applications (Cambridge University Press, London, 2006)

[2] J.H. Perepezko, Science 326, 1068 (2009)

[3] N.P. Padture, M. Gell, E.H. Jordan, Science 296, 280 (2002)

[4] J.D. Osorio, J.P. Hernández-Ortiz, A. Toro, Ceram. Int. 40, 4663 (2014)

[5] A.J. Fletcher, Thermal Stress and Strain Generation in Heat Treatment (Kluwer Academic Publishers, Dordrecht, 1989)

[6] B.J. Foss, S. Gray, M.C. Hardy, S. Stekovic, D.S. McPhail, B.A. Shollock, Acta Mater. 61, 2548 (2013)

[7] R. Burgel, P.D. Portella, J. Preuh, Superalloys 2000 (TMS, Warrendale, PA, 2000), p. 229

[8] D. Seo, P. Au, X. Huang, D. Nagy, Investigation of Recrystallization Phenomenon of Single Crystal Superalloys for Gas Turbine Applications (National Research Council, Montreal, 2006)

[9] A.J. Porter, B. Ralph, J. Mater. Sci. 16, 707 (1981)

[10] B. Tian, C. Lind, E. Schafler, O. Paris, Mater. Sci. Eng. A 367, 198 (2004)

[11] A.O.F. Hayama, H.R.Z. Sandim, J.F.C. Lins, M.F. Hupalo, A.F. Padilha, Mater. Sci. Eng. A 371, 198 (2004)

[12] K.W. Huai, J.T. Guo, Q. Gao, H.T. Li, R. Yang, Intermetallics 15, 749 (2007)

[13] B.G. Choi, C.Y. Jo, H.U. Hong, I.S. Kim, S.M. Seo, H.M. Kim, Trans. Nonferrous Met. Soc. China 21, 1291 (2011)

[14] G. Xie, J. Zhang, L.H. Lou, Scr. Mater. 59, 858 (2008)

[15] J.C. Xiong, J.R. Li, S.Z. Liu, J.Q. Zhao, M. Han, Mater. Charact. 61, 749 (2010)

[16] L. Wang, G. Xie, L.H. Lou, Mater. Lett. 109, 154 (2013)

[17] J.R. Li, Z.G. Zhong, D.Z. Tang, S.Z. Liu, P. Wei, P.Y. Wei, Z.T. Wu, D. Huang, M. Han, Superalloys 2000 (TMS, Warrendale, PA, 2000), p. 777

[18] Y.H. Chung, M.C. Shin, D.Y. Yoon, Acta Metall. Mater. 40, 2177 (1992)

[19] L.C. Zhuo, M. Huang, F. Wang, J.C. Xiong, J.R. Li, J. Zhu, Mater. Lett. 139, 232 (2015)

[20] P. Strunz, M. Petrenec, U. Gasser, J. Tobiáš, J. Polák, J. Šaroun, J. Alloys Compd. 589, 462 (2014)

[21] C.Y. Jo, H.Y. Cho, H.M. Kim, Mater. Sci. Technol. 19, 1671 (2003)

[22] S.M. Seo, H.W. Jeong, Y.K. Ahn, D.W. Yun, J.H. Lee, Y.S. Yoo, Mater. Charact. 89, 43 (2014)

[23] P. Haasen, Metall. Trans. A 24, 1001 (1993)

[24] S. Mahajan, C.S. Pande, M.A. Imam, B.B. Rath, Acta Mater. 45, 2633 (1997)

[25] M. Benyoucef, B. Décamps, A. Coujou, N. Clément, Philos. Mag. A 71, 907 (1995)

[26] X.F. Ma, H.J. Shi, Int. J. Fatigue 61, 255 (2014)

[27] C.B. Shoemaker, D.P. Shoemaker, J. Mellor, Acta Cryst. 18, 37 (1965)

[28] H.Q. Ye, D.X. Li, K.X. Guo, Acta Metall. Sin. 22, A1 (1986) (in Chinese)

[29] Q.Y. Shi, X.F. Ding, J.Y. Chen, X.N. Zhang, Y.R. Zheng, Q. Feng, Metall. Mater. Trans. A 45, 1665 (2014)

[30] R.C. Reed, T. Tao, N. Warnken, Acta Mater. 57, 5898 (2009)

[31] R.A. Hobbs, M.S.A. Karunaratne, S. Tin, R.C. Reed, C.M.F. Rae, Mater. Sci. Eng. A 460-461, 587 (2007)

[32] A. Janotti, M. Krčmar, C.L. Fu, R.C. Reed, Phys. Rev. Lett. 92, 085901 (2004)

[33] D.A. Porter, K.E. Easterling, M.Y. Sherif, Phase Transformations in Metals and Alloys (Chapman \& Hall, London, 2009)

[34] H. Wang, N. D'Souza, S.X. Zhao, D. Welton, N. Warnken, R.C. Reed, Scr. Mater. 78-79, 45 (2014) 